\title{
“PATHÉ-BABY": OS DESlizAMENTOS DA PROSA TURÍSTICA DE AlCÂntara MACHADO ${ }^{1}$
}

\author{
Danielle Crepaldi Carvalho
}

\section{INTRODUÇÃO}

António de Alcântara Machado é um descendente sui generis da aristocracia quatrocentona paulistana. Filho e neto de juristas notórios, formou-se em Direito para ingressar, ato contínuo, no Jornal do Comércio de São Paulo, como redator da coluna "Teatros e Música” (1923). Dali por diante, assumiria, a exemplo dos jovens que organizaram a Semana de Arte Moderna de 1922, o papel de desbravador de novos caminhos artísticos e literários. A função de jornalista deflagra a viagem europeia que originaria o objeto de que nos ocuparemos neste artigo, "Pathé-Baby" (MACHADO, 2002), coleção de "panoramas internacionais" compostos a bico de pena, obra cujo conteúdo e a forma implodem os limites entre

\footnotetext{
1 Este artigo não teria sido possível não fossem as reflexões suscitadas por algumas instâncias fundamentais: as disciplinas "LT oo1-A - Literatura Comparada" e "TL119-H - Textos em Teoria, Crítica e História Literária II”, ministradas pela Profa. Dra. Miriam V. Gárate, na pós-graduação e na graduação do IEL-Unicamp, no primeiro semestre de 2009 e segundo semestre de 2010 (e, depois, pelas conversas travadas durante a época da orientação de Doutorado, de 2010 a 2014); a disciplina "DE o12-A - Teoria do Cinema: Cinema Documental e Experimental - passagens”, ministrada pelo Prof. Dr. Francisco Elinaldo Teixeira na pós-graduação no IA-Unicamp, no segundo semestre de 2010; e, por fim, as conversas com a Profa. Dra. Orna M. Levin, entre 2009 e 2010, as quais deram origem a dois volumes de seletas de contos de João do Rio e Alcântara Machado, publicados pela Lazuli em 2010 e 2013. Por fim, agradeço ao Prof. Dr. Eduardo Morettin pela leitura cuidadosa e comentários extremamente profícuos a uma versão anterior deste texto.
} 
os gêneros literários (a crônica, o conto e a poesia) e entre as artes (a literatura, a pintura e o cinema), em consonância com o proceder da literatura moderna, d'aquém e d'além mar.

Após uma breve primeira escala em Lisboa, o escritor aporta em Paris, onde habitavam Oswald de Andrade e a esposa Tarsila do Amaral, dois modernistas de primeira hora. A cidade era, então, palco da Exposition Internationale des Arts Décoratifs et Industriels Modernes, vitrine onde se exibia a síntese do que de mais novo o mundo produzira nos campos das modalidades artísticas ali arroladas (LARA, 2002; MORETTIN, 2015). Embora desdenhe da Exposição Internacional nas páginas de "PathéBaby”, em prol do povo que, nas ruas, dança às barbas do evento oficial (MACHADO, 2002, p. 56), o artista não passaria por ela incólume. Sua produção literária - cronística, primeiro, uma vez que o escritor ainda não trouxera a lume nenhum volume literário impresso - altera-se sensivelmente a partir dessa experiência.

Embora, segundo Cecília de Lara (2002, p. 11), a viagem do autor tenha se dado de forma inesperada, ela logo se atrelou a um objetivo profissional: caberia a ele enviar, ao Jornal do Comércio, crônicas semanais tematizando suas andanças pelo solo europeu. Era procedimento comum, então, que os colaboradores das folhas exercessem o seu mister nas viagens internacionais que faziam, nutrindo com visões do Velho Mundo a euromania do público burguês que os lia. Embora a periodicidade semanal não tenha passado de promessa, o escritor cumpriu a função da qual foi incumbido com alguma regularidade, enviando periodicamente a São Paulo artigos para a série cronística "Pathé-Baby: panoramas internacionais" (LARA, 2002, p. 15).

Se Alcântara Machado fez-se fotografar diante dos monumentos históricos europeus, à moda dos escritores do período, o resultado literário de suas andanças seria, porém, burilado até que, uma vez organizado em volume, ficasse léguas distante da literatura produzida pelos seus confrades viajantes. Este artigo propõe-se a fazer uma leitura de "PathéBaby”, da série cronística ao volume impresso, que procure compreender a modernidade intentada pela obra, em diálogo com as tendências estéticas reverberadas pela Semana de 22 e chanceladas por eventos como a Exposição de Paris de 1925, a contrapelo dos cânones do gênero literatura de viagem. 


\section{A LITERATURA E O CINEMA EM “PATHÉ-BABY”}

A proximidade da literatura de Alcântara Machado com o cinema já mereceu notação extensiva por parte da crítica (LARA, 2002; GÁRATE, 2012; RODRIGUES, 2012). O texto enxuto do autor, com ênfase nas imagens cortantes - a despeito do âmbito descritivo - e nas elipses, fez sua escrita ser aproximada da montagem cinematográfica, cuja sistematização se dera anos antes da publicação de suas primeiras obras. "Pathé-Baby" apropria-se ostensivamente da mise-en-scène do cinema. A começar pelo título, que faz referência à câmera cinematográfica portátil produzida, a partir de 1922 (FOSTER; LEÃO, 2015, p. 344), pela Pathé - empresa que, além de produzir equipagem cinematográfica, também rodava e distribuía internacionalmente filmes. $\mathrm{O}$ livro borra as fronteiras entre as artes, ao criar uma simbiose entre a forma e o conteúdo do texto. $\mathrm{O}$ ambicioso projeto gráfico de "Pathé-Baby" dialoga com obras ruptórias produzidas desde anos antes na Europa, a exemplo dos Calligrammes de Guillaume Apollinaire (1918) - coletânea de poesia que rompe com a inscrição textual tipográfica padrão; a literatura dobrando-se literalmenteà ilustração, os textos poéticos terminando em inscrições, num só tempo, literárias e pictóricas dos objetos (APOLLINAIRE, 1918). Alcântara Machado inaugura, nesse volume, um procedimento que dali por diante lhe será corrente: a introdução, na cena literária, da polifonia da cidade moderna, na qual convergiam vozes, músicas, ruídos, cores e sabores. Exacerba-se formalmente, em sua obra, o quanto índices da modernidade, como os automóveis e os trens cada vez mais velozes, a fotografia, os anúncios luminosos e a cinematografia haviam alterado a percepção do mundo e, por conseguinte, a literatura.

O título da série de artigos publicados no Jornal do Comércio já prenunciava a proximidade que o seu criador desejava estabelecer com o suporte cinematográfico. Em "Pathé-Baby: panoramas internacionais", Alcântara Machado repetia o procedimento de cronistas brasileiros que desde o século anterior associavam o gênero cronístico a novidades técnicas voltadas ao registro "objetivo" da realidade, como a fotografia, o kinetoscópio e o cinema, batizando suas séries segundo os campos semânticos dessas artes (vejam-se os "Instantâneos" de Coelho Netto, o "Kinetoscópio" de Elvira Gama, ou o "Cinematógrafo" de João do Rio). ${ }^{2}$

2 Elvira Gama publicou a série cronística "Kinetoscópio", sob o pseudônimo de Edisonina, no Jornal do Brasil, a partir de dezembro de 1894; Coelho Netto publicou "Instantâneos", sob o pseudônimo de N., no Correio da Manhã, a partir de junho de 1904; João do Rio 
O espaço ambivalente ocupado pela crônica no interior da literatura favorecia a aproximação.

O gênero desenvolveu-se, no século XIX, a meio do caminho entre a ficção e a história. Se os primeiros registros cronísticos, datados do século XVI, dedicavam-se a historiar os feitos dos "grandes homens", com o passar dos tempos e o deslocamento do gênero para os meios de comunicação em massa, ampliou-se a gama de assuntos tratados e as tonalidades dos textos - a resvalarem ora para a brejeirice, ora para a melancolia, ora para a virulência (DIMAS, 1974, pp. 46-49). O registro do real misturava-se paulatinamente à ficcionalização. No interior do jornal, suporte obrigado ao imediatismo, o cronista era a um só tempo jornalista e artista - dotado de um olho fotográfico, captava a realidade para depois transformá-la em arte.

Os "panoramas internacionais" compostos pela Pathé-Baby de Alcântara Machado já acenavam para esta dupla dimensão: se se obrigavam, como o título explicita, ao esquadrinhamento, através da distância, de amplas superfícies - registro foto-cinematográfico pautado pela objetividade -, igualmente se debruçavam na construção de imagens cuja densidade pertencia mais ao domínio da poesia que da reportagem jornalística. Poesia, vale sublinhar, quase nunca ditirâmbica. As informações que os brasileiros recebiam da Europa a partir da pena do autor iam a contrapelo da prosa elogiosa que dava forma às percepções dos colaboradores das folhas que se dedicavam, em solo estrangeiro, ao mesmo ofício.

O trecho inicial do episódio referente à sua viagem de ida a Lisboa denuncia a estratégia iconoclasta: "Lama no Tejo. Manhã horrível de céu cinzento. Chuvinha fina que cai. Frio. Vento. A lancha pula sobre as vagas: desce, sobe, torna a descer, torna a subir. Uma bola de borracha saltando" (MACHADO, 1925, pp. 3-4). A apreensão crua da cidade com a qual os brasileiros tinham tão fortes laços históricos - motivo de crítica ferrenha ao autor por parte de anônimos que escreviam ao jornal, reclamando, conforme lembra Cecília de Lara (2002) em sua análise da recepção dessa série cronística - explicita outro procedimento que será corrente na

publicou "Cinematógrafo", sob o pseudônimo de Joe, na Gazeta de Notícias, a partir de agosto de 1907 - organizando, posteriormente, alguns escritos desta e de outras séries suas, no célebre volume Cinematógrafo (1909). Essa relação não se quer, de modo algum, exaustiva - as potencialidades da fotografia e de seus sucedâneos foram, em fins do século XIX, objetos privilegiados de reflexão por parte dos cronistas, a exemplo de Edisonina (1894, p. 1), N. (1904, p. 1) e Joe (1907, p. 1). A esse respeito, cf. Carvalho (2014). 
escrita do autor, plenamente corroborado pelo título que ele dá à sua obra: a eliminação dos conectivos e das subordinadas em prol de um fraseado lancinante, de cortes secos, à moda da decupagem cinematográfica (em especial daquela realizada pelo cinema Avant-garde produzido na Europa, cujo exemplo modelar é o Ballet mécanique de Fernand Léger, sobre o qual tratarei logo mais). Não obstante, o tédio que toma o autor enquanto a lancha "pula sobre as vagas" feito bola é desenhado por assonâncias que ecoam os ruídos da chuva e do vento, potencializando as suas sensações.

O estilo do autor ainda seria burilado para a publicação da obra em volume, visando à maior fluência do texto e adoção de um sistema ortográfico simplificado - na esteira do que estudiosos como Gonçalves Viana haviam proposto no início do século XX (LARA, 2002, p. 28). O repúdio à verborragia da literatura pregressa tornara-se uma das principais bandeiras do Movimento Modernista (MACHADO, 1983, p. 246). Para se contraporem aos "medalhões" literários, os jovens modernistas elegeram o cinema como a arte que representava de forma mais bem acabada o século XX, preferindo, sem rebuços, Pearl White a Sarah Bernhardt: "Sarah é tragédia, romantismo sentimental e técnico. Pérola é raciocínio, instrução, esporte, rapidez, alegria, vida” (KLAXON, 1922, p. 2). Preferindo, noutras palavras, a azáfama moderna protagonizada pela diva do cinema silencioso aos transes sentimentais da diva maior do teatro declamado francês.

Embora certos traços do Modernismo de primeira hora fossem, com o tempo, suavizados, ${ }^{3}$ certos preceitos ali estabelecidos foram utilizados como baliza à produção artística posterior. Como, por exemplo, o recurso ao mimetismo da linguagem cinematográfica por parte da literatura. Se a coluna de crônicas "Pathé-Baby" procura uma linguagem enxuta, em referência ao campo semântico do cinematógrafo, o livro oriundo dela reproduz os mais diversos âmbitos do espetáculo cinematográfico com riqueza de detalhes (e, sublinhe-se, com uma pitada larga de ironia).

Para começar, o autor assume o foro de companhia cinematográfica, apresentando ao leitor-espectador seu livro-filme. Colabora com ele Antônio Paim Vieira, o Paim, desenhista com larga experiência, ilustrador de revistas de maior ou menor tiragem (desde Fon-Fon! e Para todos a Ariel, revista literária de qualidade gráfica superior), participante da Semana de

3 Em 1924, Alcântara Machado escreveria mesmo uma delicada crônica, criticando o tratamento incabível dado à memória de Bernhardt por parte de um cronista italiano. Cf. Machado (1983, pp. 73-76).

Remate de Males, Campinas-SP, v. 37, n. 1, pp. 385-407, jan./jun. 2017 
1922 em obras coproduzidas com o colega Yan de Almeida Prado, ilustrador de obras literárias (desde 1920, quando ilustrou As máscaras, de Menotti Del Picchia) e autor de motivos decorativos crescentemente interessados por temas nacionais (CAVALCANTI, 1928; AMARAL, 2005, pp. 259-260).

Não pertence ao escopo deste artigo pensar detidamente na evolução artística de Paim, mas não podemos passar ao largo das semelhanças existentes entre suas ilustrações para "Pathé-Baby" e os pôsteres que artistas como Robert Bonfils e Charles Loupot realizaram para a Exposição de Paris de 1925. Num e noutros há um análogo despojamento da ornamentação e a preferência pelos ângulos geométricos da Art Déco, em detrimento dos rococós da Art Nouveau, à maneira das vanguardas europeias de princípios do século XX, como o Cubismo. Conforme o título da Exposição deixava transparecer, seu objetivo era atrelar a arte e a indústria moderna: daí, por exemplo, a magnificência da fumaça cinzenta que brota da indústria, no pôster que Loupot concebe para a Exposição. O louvor aos índices da modernidade, máxima de movimentos vanguardistas como o Futurismo europeu - e, em sua esteira, o primeiro Modernismo brasileiro -, é corroborado não apenas pela ironia por meio da qual Alcântara Machado se refere às cidades-berço da civilização ocidental, como se verá no curso deste artigo, mas também por meio da ilustração de Paim.

\section{ALCÂNTARA MACHADO, PAIM E A EXPOSIÇÃO INTERNA- CIONAL DE 1925}

Salvo excepcionalmente Gárate (2012), a ilustração de Paim em "Pathé-Baby" não é explorada a contento por parte da crítica, sendo não raro tomada meramente como adorno ao volume. ${ }^{4}$ Percebe-se, por parte do artista, um trabalho autoral de construção de sentido, em diálogo com a prosa de Alcântara Machado, no entanto sem a preocupação com a figuração em moldes realistas daquela prosa. Alinhado aos preceitos artísticos inaugurados pelas vanguardas, Paim opta pela xilogravura, pelos traços grossos, voltados mais a silhuetar o objeto que a impô-lo ao

\footnotetext{
4 Rodrigues procura ir além desse viés, notando um duplo papel dessas ilustrações, o de permitirem "a leitura das crônicas como se fossem episódios fílmicos reproduzidos na página do livro” e de reproduzirem o contexto de exibição cinematográfica da época (a exemplo da movimentação dos músicos) - não explorando, no entanto, a questão, no intuito de demonstrar como as imagens funcionam na economia do volume (RODRIGUES, 2012, p. 8).
}

Remate de Males, Campinas-SP, v. 37, n. 1, pp. 385-407, jan./jun. 2017 
leitor em seus detalhes objetivos. Opera, ademais, a decomposição das figuras, apresentadas segundo seus detalhes geométricos, afastando-se, assim, dos cânones clássicos da perspectiva - à moda das figuras cubistas de Pablo Picasso ou Fernand Léger.

Destaque-se, aqui, o diálogo estabelecido entre o Cubismo e a Sétima Arte, algo explicitado pela presença de um homem como Léger na produção cinematográfica vanguardista dos anos de 1920. Paim rompe com a perspectiva convencional, multiplicando os pontos de vista e instaurando o caos em suas imagens repletas de informação: a exemplo daquela que abre a sequência "Paris", na qual convergem pessoas dos mais diversos biótipos, entre a passividade e a gritaria, além de carros, de instrumentos musicais e de um preponderante Arco do Triunfo que se inclina, como que a dançar ao ritmo da "Java" parisiense, cujo letreiro garrafal o encima (MACHADO, 2002, p. 47). O imaginário da Cidade Moderna, de que a metrópole francesa é modelo, ganha, por meio do traço do artista brasileiro, uma imagem figurada que enfatiza a sua polifonia.

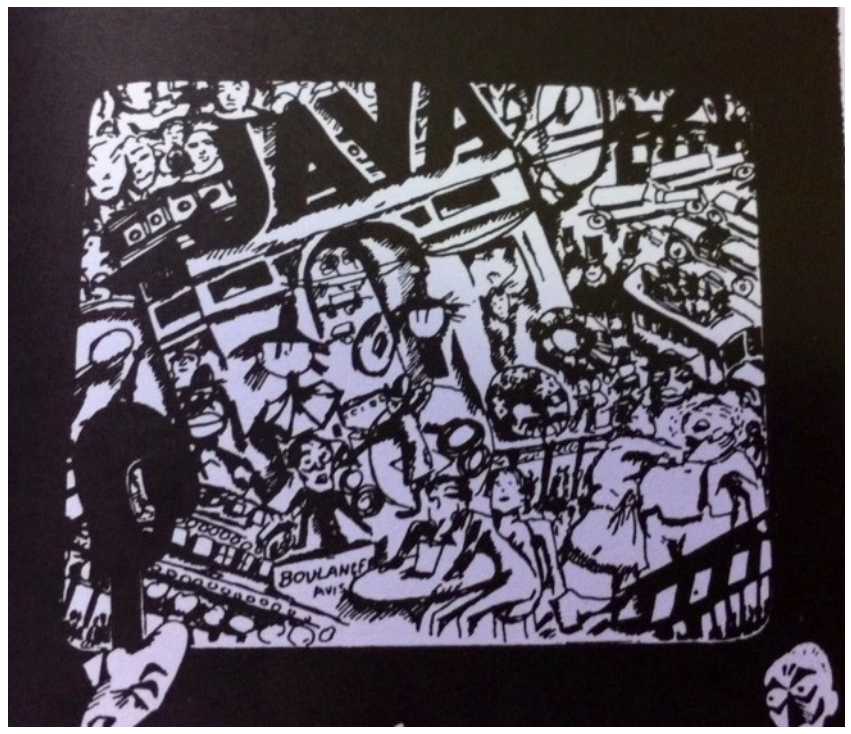

Figura 1. Xilogravura de Paim: Paris.

Fonte: Machado (2002).

O Cinema - notadamente o avant-garde - muito colaborou para a divulgação das vanguardas europeias. A ilustração de Paim, impressa em "Pathé-Baby", lembra obras-primas da cinematografia vanguardista, a exemplo de Berlim, sinfonia de uma metrópole, de Walter Ruttmann 
"Pathé-baby": os deslizamentos da prosa turística de Alcântara Machado - 392

em 1927 - esforço notável de mimetizar em película a azáfama da cidade moderna. ${ }^{5}$ Não se trata, neste caso, de apontarmos a influência dessa obra de Ruttmann sobre Paim, dado que a primeira só foi concluída dois anos mais tarde, e veiculada no Brasil apenas em 1929 (MACHADO JR., 1989, p. 25). Cumpre aqui assinalar o intercâmbio havido, então, entre essas artes, sobretudo no âmbito da produção vanguardista.

A Exposição de Paris, em seu esforço de alinhar arte e indústria, não poderia deixar de voltar os holofotes à cinematografia, arte que, por excelência, é criada pela técnica. O décimo dos treze volumes do Catálogo da Exposição detalha de que forma o cinema participou do evento. Denominado "Théâtre, Photographie et Cinématographie", o volume tem a sua segunda porção dedicada à fotografia e à cinematografia, artes homólogas devido à matéria que as origina: a fotografia é a imagem obtida sobre uma superfície fotossensível por meio da ação da luz; enquanto que o cinema é a fotografia em movimento. No que toca à cinematografia, há uma refletida ponderação sobre os caminhos desta arte, no âmbito francês e no estrangeiro, incluídas suas vertentes mais ou menos populares. Ponderação que já se apresenta no primeiro volume do Catálogo, no qual se reflete acerca da relevância dessa arte para o delineamento da sociedade moderna.

Assim, a última evolução das artes se revelava como uma pulsante orquestração de grupos de imagens, uma arquitetura em movimento, mais capaz que qualquer outra língua estética de exprimir a vida de hoje, a alma moderna. Como as artes plásticas, ela faz ver; como a música, ela ritma; como o romance, ela narra; como o teatro e a dança, ela se move. Essa complexidade explica a abundância de seus meios técnicos que tocam os teclados do tempo e do espaço: a câmera lenta e o movimento acelerado, as tomadas em plongée e em contraplongée, as deformações obtidas por jogos de vidros ou objetivas especiais, o borrão, a aparição progressiva de uma imagem sobre outra, ou fading cruzado, a superimpressão, os jogos de escala, desde o close up, que assume uma visão bastante aproximada, até o long shot, que evoca a mais distante das aparições. Ela indica também certas necessidades, como a especialização dos gêneros, do filme descritivo ao poema luminoso, abstrato como uma fuga musical. Ela faz compreender, enfim, as dificuldades extremas que o artista experimenta para realizar as sínteses harmoniosas, considerando-se tal riqueza de elementos (FRANCE, 1931, pp. 77-78, tradução nossa). ${ }^{6}$

5 Gárate (2012, p. 393) explora essa aproximação com justeza.

6 "Ainsi, le dernier venu des arts se révélait comme une puissante orchestration de groupes d'images, une architecture en mouvement, plus capable qu'aucune autre langue esthétique d'exprimer la vie d'aujourd'hui, l'âme moderne. Comme les arts plastiques il fait voir; comme la musique il rythme; comme le roman il conte; comme le théâtre \& la danse il se meut. Cette complexité explique l'abondance de ses moyens techniques qui jouent sur les Remate de Males, Campinas-SP, v. 37, n. 1, pp. 385-407, jan./jun. 2017 
Na primeira metade dos anos de 1920, já a linguagem cinematográfica estava sistematizada, construindo-se, a narrativa, por meios eminentemente visuais - estamos ainda no âmbito do cinema silencioso. Mister efetivado por meio da técnica: o olho da câmera captava o objeto a partir de distanciamentos, angulações e velocidades variadas. Caberia, por fim, ao artista, a criação de "sínteses harmoniosas", como diz o catálogo, das tomadas que realizara, ou seja, a montagem desse material. A possibilidade de manipular tempo e espaço permite mesmo a coexistência de duas diferentes temporalidades - através da técnica da superimpressão, ou da partição do quadro -, fazendo emergir objetivamente a sensação de agilidade da vida moderna. ${ }^{7}$

Os procedimentos do cinema deslizam-se para a pintura ea ilustração. Daí ao Cubismo desdobrar os sujeitos tridimensionais, chapando-os na superfície plana da tela. Ou à arte de Paim fazer convergirem, num mesmo quadro, toda uma fauna humana e uma arquitetura apresentadas ao longo de vários subcapítulos de "Pathé-Baby", ora inserindo-as num mesmo ambiente, ora seccionando o quadro de modo a introduzir, nele, várias cenas diferentes; ora, ainda, torcendo risonhamente o sentido do texto de Alcântara Machado, por meio da combinação, numa mesma imagem, de elementos verbais aleatórios, potencializando a ironia do escritor.

Paim realiza, para a criação das imagens em "Pathé-Baby", operações análogas às feitas pela montagem cinematográfica. A verborragia tornarase anacrônica, afirmava Alcântara Machado - o que determinava a preferência, por parte dos jovens da Klaxon, às películas de Pearl White, em detrimento da atuação de Sarah Bernhardt. Ou a concepção, por parte do autor de "Pathé-Baby", de uma prosa despida de ornamentações, voltada aos lampejos de imagens lancinantes em detrimento da narrativa caudalosa - projeto literário que ele nutriu durante toda a vida, nos campos da crônica jornalística e da prosa literária.

A Exposition Internationale des Arts Décoratifs et Industriels Modernes de 1925 veio legitimar a relevância da intervenção artística

claviers du temps \& de l'espace: le ralenti \& l'accéléré, les prises de vues en plongée ou en contreplongée, les déformations obtenues par jeux de glaces ou objectifs spéciaux, le flou, l'apparition progressive d'une image sur une autre ou fondu enchainé, la surimpression, les jeux d'échelle, depuis le 'close up' qui suppose une vision très rapprochée jusqu'au 'long shot' qui évoque l'apparition la plus lointaine. Elle indique aussi certaines nécessités, comme la spécialisation des genres, du film descriptif au poème lumineux, abstrait comme une fugue. Elle fait comprendre enfin les extrêmes difficultés qu'éprouve l'artiste à réaliser d'harmonieuses synthèses avec une telle richesse d'éléments."

7 Reflexões paulatinas sobre essa relação se encontram em Xavier (1978, pp. 158-163).

Remate de Males, Campinas-SP, v. 37, n. 1, pp. 385-407, jan./jun. 2017 
oriunda das vanguardas europeias. Considerando-se o papel simbólico das "Exposições Universais", de fomentarem uma "carnificina do espírito" - construindo simbolicamente um mundo novo, presidido pelos índices da tecnologia (MORETTIN, 2005, p. 140), sobre as ruínas simbólicas e mesmo empíricas do mundo antigo (já que, não nos esqueçamos, a Europa vinha de emergir da Primeira Grande Guerra) -, percebe-se a dimensão que teve tal evento na consolidação do novo panorama artístico mundial e, por conseguinte, na configuração da obra do autor de que nos ocupamos.

As construções imponentes da exposição, situadas numa região estratégica de Paris - entre a esplanada dos Invalides e o entorno do Petit e do Grand Palais, passando pelo mítico rio Sena -, foram eternizadas por um laudo catálogo em treze tomos que lhe ecoava a grandiosidade. Documento cujas linhas destronam o mimetismo realista produzido pela arte ao longo dos séculos: esforço que teria sido primeiro empreendido pelo teatro e, em sua esteira, pela pintura, pela música, pela literatura e pelo cinema. Os cenários que reproduziam estritamente a realidade deixavam de lado, segundo o catálogo, uma característica intrínseca ao teatro: a de que ele era "filho da mentira", uma vez que a realidade objetiva da sala de espetáculo confrontava-se com o âmbito ficcional construído pela obra (FRANCE, 1931, p. 73).

Tal percepção teria levado o teatro moderno a compor encenações que primassem por sugerir, deixando-se de lado a reconstituição realista -, transformando as linhas, as cores e os ritmos em porção preponderante do espetáculo, a despeito mesmo do trabalho dos atores. Tarefa empreendida com o mesmo ímpeto pelas artes plásticas, voltadas sobretudo à geometria e à cor; bem como pela música, ao destituir o verismo; pela literatura, ao deixar de lado os excessos descritivos; e pelo cinematógrafo, o qual teria por única matéria "um retângulo de pano branco", bastando-lhe "os reflexos, os fantasmas” do ator (FRANCE, 1931, pp. 72-75).

De acordo com o catálogo, a matéria de que se constituía o cinema realizaria o ideal das vanguardas, de deposição do histórico ensejo da arte de duplicação da realidade (tarefa de saída inglória, uma vez que os âmbitos da realidade e da arte são, por definição, gerados por materiais diferentes), criando-se, ao contrário, uma matéria homogênea, feita de luz. Não compete a nós tecermos a crítica à teoria ali formulada.

Estudiosos como Auerbach (1971) e Antonio Candido (1970), por exemplo, se debruçaram sobre a mimese literária, pensada enquanto 
homologia da realidade, e não tentativa de sua macaqueação. ${ }^{8}$ No que toca ao cinema, porção não desprezível de seus primeiros pensadores admiravam-no por razão inversa à apontada pelo catálogo, ou seja, pelo que ele teria de cópia "objetiva" da realidade, já que realizada através de meios puramente técnicos.

Cumpre atentarmos à reflexão impressa no catálogo enquanto sistematização das coordenadas artísticas das vanguardas. No que toca ao cinema, estabelece-se uma bipartição dos filmes rodados nos anos de 1920: de um lado, os preferidos do público, os filmes "essencialmente visuais", "muito distanciados do teatro mudo", porém, "cativantes, humanos"; de outro, o "cinema puro", abstrato, no qual as imagens se sucediam segundo um ritmo rigoroso, mas se voltavam a si mesmas, em detrimento do “assunto" (FRANCE, 1929, pp. 76-77 e 197). No entanto, se porção dos artistas de vanguarda do período efetivamente produziu filmes voltados às formas abstratas (como Walter Ruttmann, que rodou, entre 1921 e 1925, os Opus I, II, III e IV; ou Viking Eggeling, autor da Symphonie diagonale, de 1924 - bailados ritmados de formas geométricas), ${ }^{9}$ parte considerável eles equilibrou-se entre a abstração e a narratividade. ${ }^{10} \mathrm{~A}$ esses últimos, a Exposição volta especial interesse.

Exemplo cabal é Fernand Léger, artista por quem Alcântara Machado demonstra, em seu "Pathé-Baby", nutrir grande simpatia." O Catálogo da Exposição lista a obra L'inhumaine, de Marcel L'Herbier (1924), que teve Léger entre seus diretores de arte: coube ao artista a execução do

8 Devo a lembrança da referência ao seminal artigo de Candido, "Dialética da malandragem", ao professor Marcos Napolitano, da ECA-USP.

9 Lembremos que o abstracionismo estava na ordem do dia também no plano musical, instaurado por compositores como Arnold Schönberg a partir da observação da obra de um artista como Wasilly Kandinsky. A pintura dos abstracionistas da aurora do século XX, liberta dos liames com a figuração, leva o compositor austríaco a intentar um sucedâneo no âmbito sonoro. Schönberg rompe com a tonalidade, abolindo convenções musicais como a repetição, responsável pela memorização dos trechos musicais e, portanto, por sua popularidade. Isso faz emergir uma característica fundamental da música: a inexistência de um "significado" absoluto a brotar das notas. A liberdade que é parti pris dessa arte seduz, por sua vez, o pintor russo, daí a relação que Kandinsky e Schönberg estabelecem entre si, a partir dos anos de 1910. Uma reflexão mais detalhada a este respeito encontra-se no Catálogo da Exposição "Kandinsky: tudo começa num ponto", exibida em São Paulo no Centro Cultural Banco do Brasil (2015). Cf. também Coelho (2015, p. 24).

10 Morettin (2015) constata a exclusão de obras abstratas rodadas à época, como Ballet mécanique, de Fernand Léger e Dudley Murphy (1924) ou Entr'acte, de René Clair (1924).

11 Saindo de uma galeria veneziana repleta da iconografia religiosa renascentista, o prosador modernista afirma: "Os olhos modernos saem ansiando por uma tela dinâmica e liberta de Léger” (MACHADO, 2002, p. 112).

Remate de Males, Campinas-SP, v. 37, n. 1, pp. 385-407, jan./jun. 2017 
cenário do laboratório, apresentado, no catálogo, sob a inscrição "Planche LXXXIII" (FRANCE, 1929, p. 83). ${ }^{12}$ A imagem - abaixo, um fotograma dessa sequência do filme - dá a ver a preferência do artista pela forma geométrica em detrimento da figuração objetiva da realidade, dando-se relevo a um mundo da técnica que encontra consonância no ambiente de trabalho do jovem cientista representado no filme. Todavia, precisamos sublinhar que a cenografia moderna converge, no filme, para uma narrativa que não escamoteia seus lastros com o melodrama - gênero que, pela tipificação dos caracteres que empreendia, era um dos mais populares e vendáveis da cinematografia mundial.

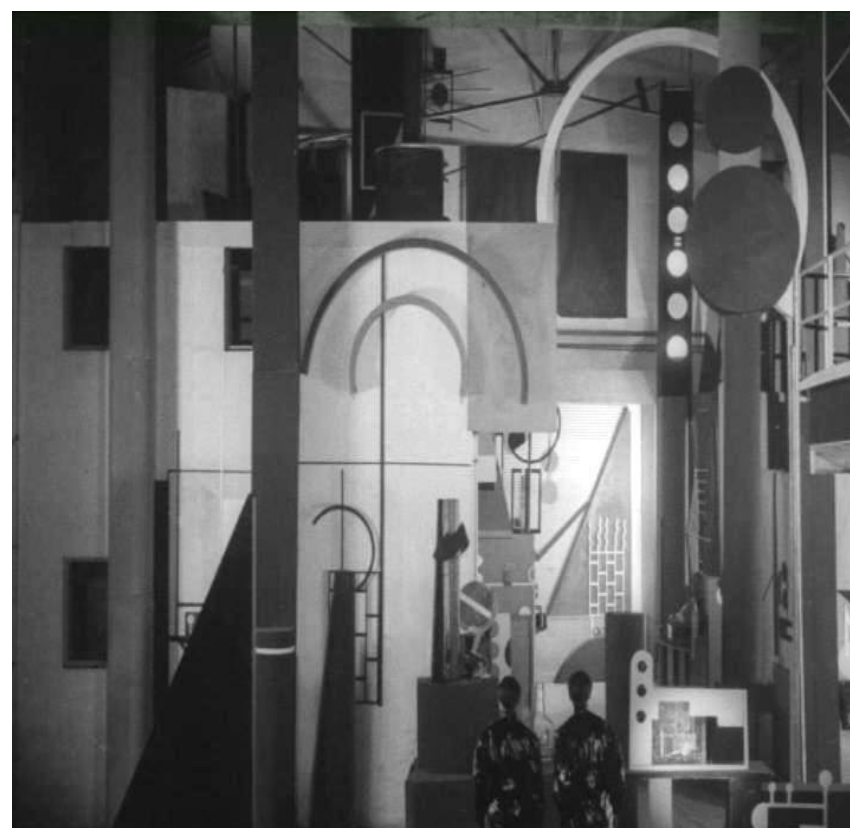

Figura 2. Fotograma da sequência do laboratório, do filme L'inhumaine (L'HERBIER, 1924), sequência cuja direção de arte é de Léger.

L'inhumaine promove um deslizamento no que toca ao mainstream cinematográfico, o qual encontra consonância na factura de "Pathé-Baby". O filme narra a história de Claire Lescot, a "inumana" do título, célebre prima-dona que tem os homens aos seus pés. Um deles é Einar Norsen, jovem cientista que decide cometer suicídio após ser desdenhado por ela.

12 No tocante à Exposição, Fernand Léger foi também um dos responsáveis pelo hall de entrada do pavilhão de uma embaixada francesa, além de ter executado pinturas murais para o pavilhão "L'Esprit Nouveau", de autoria de Le Corbusier. Cf. Mallet-Stevens [s.d.]. 
O entrecho romântico não passa, porém, de artifício para a exacerbação das últimas evoluções inerentes à arte moderna, tendo a direção de arte do filme escalado, para a composição dos ambientes, artistas vanguardistas de projeção no período.'3 Gesto análogo ocorre com "Pathé-Baby", obra na qual a mise-en-scène cinematográfica dobra-se a um esforço estético voltado à ruptura dos velhos paradigmas artísticos, visandoà Modernidade reverberada de modo altissonante pelos jovens de 1922.

\section{ENTRE AS VANGUARDAS EUROPEIAS E O CINEMA NARRA- TIVO: OS DESLIZAMENTOS DE "PATHÉ-BABY”}

Enformados em volume, os "panoramas internacionais" que Alcântara Machado havia distribuído a granel pelo Jornal do Comércio têm reforçados os seus liames com o cinema. Abrem-se com a xilogravura que é leitmotiv da obra, representando, na porção inferior, um quarteto de músicos; e, na porção superior, a tela branca, já tomada pelos letreiros do filme-livro "Pathé-Baby", apresentando-se Alcântara Machado à maneira de produtor (LARA, 2002; GÁRATE, 2012; RODRIGUES, 2012). O índice é denominado "Programa" e apresenta, à maneira de anúncio, os capítulos/ atrações que se seguirão. À medida que avança o programa desse sucedâneo de cinematógrafo (e, por extensão, os capítulos do livro), a tela ganha os contornos da cidade sobre a qual fala o escritor. Tais contornos, jocosos, resvalam seu humor mesmo para a porção inferior da tela, já que Paim tem o cuidado de ir despedindo paulatinamente os músicos da cena - até que, no último "filme" do programa, apenas o contrabaixista macambúzio cria a trilha incidental da cidade de Toledo; trilha grave, como sói ao instrumento, a contrapelo da conhecida calidez musical da Espanha.

O campo semântico do cinematógrafo comparece, ainda, na campainha que anuncia o início do programa, a qual se superpõe aos créditos do livro, torcidos à maneira de Apollinaire até ganharem o formato de uma película cinematográfica; na introdução dos títulos dos filmescapítulos, antes de cada litografia; na inserção, no fecho do programa, da ilustração de uma câmera Pathé-Baby, a repousar em seu tripé. A "PathéBaby” de Alcântara Machado tem a função programática de substituir

13 São eles, além de Léger, Claude Autant-Lara, Pierre Chareau, Michel Dufel e Robert Mallet-Stevens. Destaque-se que a direção de arte do filme ficou a cargo de Autant-Lara e do brasileiro Alberto Cavalcanti, que em 1926 dirigiria Rien que les heures, pioneira "sinfonia metropolitana”. Cf. Cavalcanti (1952).

Remate de Males, Campinas-SP, v. 37, n. 1, pp. 385-407, jan./jun. 2017 
a mise-en-scène da Literatura pela mise-en-scène do Cinema - gesto iconoclasta que encontra eco no próprio conteúdo do livro, alinhado às palavras de ordem dos manifestos das vanguardas.

A forma mais cabal de compreendermos tal gesto em sua complexidade será comparando o fazer literário de Alcântara Machado ao de um escritor da geração que o antecedeu. João do Rio, por exemplo, também jornalista (autor, ao longo de anos, da série cronística "Cinematógrafo", também enformada num volume que procurava sublinhar seus vínculos com a cinematografia), citado formalmente por Oswald deAndrade na telegráfica "Carta-oceano" que serve de prefácio à edição impressa de "Pathé-Baby". Adepto da literatura de viagem, João do Rio deixou textos como "Maria Madalena" (publicado em forma de folhetim jornalístico em 1917, e no volume Rosário de ilusão, em 1921), conto que apresenta uma turgidez narrativa à moda da prosa realista, voltada ao registro "fotográfico" dos sujeitos e situações. ${ }^{14}$

Ao dialogar com o eu-narrativo, a Maria Madalena bíblica faz emergir, diante dos olhos do leitor, séculos da tradição literária associada à personagem. Seu percurso de prostituta a santa desnuda-se simbolicamente diante do narrador-personagem, na transformação da Madalena de Ticiano na Madalena de Donatello, depositada no Batistério de Florença. O percurso de um quadro a outro se dá, empiricamente, através do palmilhar do narrador pelas ruas da cidade italiana, explicitado com riqueza de detalhes ao longo do texto, à moda dos roteiros turísticos. Embasa o seu movimento um esforço encetado pelas artes a partir de fins do século XVII - época de desenvolvimento exponencial da Cartografia -, e radicalizado pelo Romantismo dos anos de 1770-1830, de se incursionar pelo mundo como forma privilegiada de conhecê-lo, explicitando-se o resultado das observações nas formas de telas e textos de ressaltado colorido pitoresco (PINACOTECA, 2015).

Alcântara Machado bate-se de forma categórica contra essa tradição explicitada pelo conto de João do Rio, procedendo, para tanto, a uma quebra de forma e fundo com relação ao modus operandi da literatura do oitocentos, ainda muito pulsante na entrada do novecentos. Na linguagem, ao romper com a discursividade em prol de um texto que prima pela

14 "O seu lábio fendia-se na polpa de uma granada, os cílios eram sombras de asas, o seu olhar olhava sem olhar, chamando. Na pele de aurora, nas narinas, na testa estreita e polida, nas espáduas, de onde nascia o cálice da cabeça, latejava o desejo." (JOÃO DO RIO, 2010, p. 198).

Remate de Males, Campinas-SP, v. 37, n. 1, pp. 385-407, jan./jun. 2017 
economia narrativa: expurgando a adjetivação excessiva e substituindo as orações coordenadas pela justaposição ágil de ideias, visando mimetizar a sensação de onipresença tornada possível, então, pelas artes, nas chaves popular e erudita - pela montagem cinematográfica, de um lado; e por vertentes das vanguardas europeias (o Cubismo de Picasso e Léger, os Calligrammes de Apolinnaire), de outro. No plano do conteúdo, o pitoresco tradicional dá lugar a um viés crítico, que observa a cidade-monumento no que ela tem de exploração mercadológica ("Isso porque Dante é maior do que Florença. Ao lado de Beatrice, gentil Madonna, é vendido em mármore, bronze, couro e papel”, "Custa às vezes vinte cêntimos. Às vezes não vale”; MACHADO, 2002, p. 110), além de questionar o valor dos objetos artísticos que ela expõe - negando-lhe a "aura" que lhe atribuíra a tradição.

\begin{abstract}
Na Galleria degli Uffizi, visitantes domingueiros arrastam os pés. Compõem um ar entendido diante da Vênus lambida, manjar branco sem açúcar, da Nascita botticelliana. Empanturram-se com as mil e uma variantes da Vergine col bambino, com ou sem acompanhamento de santos; da Madonna in trono, só ou não, bonita ou feia; da Adorazione dei Magi; da Annunziazione; da Sacra Famiglia; da Deposizione; da Assunzione; da Crocrefissione. [...]

As galerias italianas negam a invenção humana. [...]

Os olhos modernos saem ansiando por uma tela dinâmica e liberta de Léger (MACHADO, 2002, p. 112).
\end{abstract}

Inserido no subcapítulo denominado "Tesouro de preciosidades", o excerto acima caminha a contrapelo da hagiografia, numa leitura irônica que transforma a arte acadêmica em repasto de gosto duvidoso, para o burguês cujas "adiposidades cerebrais" Mário de Andrade acintosamente cantara anos antes, em "Ode ao burguês". O campo semântico oriundo da alimentação é explorado com alguma pertinácia por Alcântara Machado: a Vênus é um "manjar branco sem açúcar" do qual os visitantes "empanturram-se”; e a temática dos quadros é apresentada à guisa de menu, as Virgens variando em versões "com ou sem acompanhamento de santos". A referência alimentar perdura, na menção aos "brasileiros gordos" iluminados pelo sol da Piazza della Signoria e pelo subcapítulo "engorda", imediatamente posterior (MACHADO, 2002, p. 113).

A iconoclastia é programática em "Pathé-Baby". As ruínas dos séculos, nas quais o Romantismo encontrara o "sublime" e o "belo" - e, portanto, o digno de registro "pictórico" / "pitoresco" -, são submetidas a análogo tratamento demolidor, por parte do autor: "Degraus carcomidos. Musgo. Moscas". O “Teatro romano" aparentava "vinte e dois mil anos" 
(MACHADO, 2002, p. 111). Como o poema-manifesto lido por Mário de Andrade nas escadarias do Teatro Municipal de São Paulo - reduto burguês por excelência -, durante a Semana de 22, Alcântara Machado intenta uma ruptura contumaz com a arte que o antecedera. Mesmo os mecanismos narrativos do poeta e do prosador são análogos.

"Ode ao burguês" caminha na contracorrente do elogio que o título anuncia, do mesmo modo que o "Tesouro de preciosidades" de Alcântara Machado apenas veiculará verrinas às obras Renascentistas. E ambos os autores se utilizam de paralelismos, enumerações, rimas e homologias nominais tendo em vista a ênfase de seu enfado/repúdio diante do status quo: no caso de Alcântara Machado, a citação exaustiva dos pintores ea rima final em "one" das temáticas dos quadros ("Adorazione", "Annunziazione" etc.) glosam a repetição que era traço característico do Renascimento; da mesma forma como os vocábulos "burguês" e "homem", de Mário de Andrade, desdobram-se de substantivos a adjetivos ("burguês-níquel", "burguês-burguês", "homem-curva”, "homem-nádegas”, "homem”), construindo-se, por meio da forma, a monotonia do grupo que era "sempre um cauteloso pouco-a-pouco!" (ANDRADE, 1983, p. 44-45).

Alcântara Machado (2002, p. 112) concluirá sua visita à Galleria degli Uffizi clamando por "uma tela dinâmica e liberta de Léger". À demolição retórica dos esquemas composicionais clássicos se sucede uma escritura que busca produzir, por meio da pena, os traços estilísticos do artista francês. A sequência em questão, denominada "concerto", aproxima o ambiente florentino das figuras geométricas, à maneira de Léger: "as pontes são parábolas brancas", "as janelas abertas dos forasteiros põem trapézios de luz na fachada dos hotéis". ${ }^{5}$ Brigitte Hedel-Samson (2009, p. 17) ressalta a "grande unidade de estilo" das pinturas de Fernand Léger produzidas na década de 1920, nas quais há a valorização das formas em detrimento dos temas: assim, naturezas-mortas, paisagens, retratos, tudo se dobra à geometria. ${ }^{16}$

15 Num subcapítulo referente ao coração de Londres essa analogia já havia sido traçada. Naquele caso, todavia, o lançar d'olhos do autor pela cidade moderna fá-lo enxergar um quadro de cores mais vibrantes: "Os anúncios luminosos [...] põem na tela desigual da multidão que não para pinceladas de Léger e Delaunay, vermelhas, azuis e verdes, depois de novo verdes, azuis e vermelhas" (MACHADO, 2002, pp. 77-78). O ataque ao Renascentismo e à arte italiana desse período está em acordo com a postura dos futuristas, daí o elogio à capital inglesa.

16 Veja-se, por exemplo, "A xícara de chá" / "La tasse de thé" (1921) e "Natureza-morta A. B. C." / "Cachos de uva e peixe" / "Grappes et poisson" (1927), reproduzidos no mesmo catálogo. Cf. Hedel-Samson (2009, pp. 19 e 22).

Remate de Males, Campinas-SP, v. 37, n. 1, pp. 385-407, jan./jun. 2017 
A referida unidade remete ao desejo de experimentação dos vanguardistas, voltados à materialidade dos objetos sobre o quais trabalhavam - às tintas e às formas geométricas a partir das quais se burilam as imagens, no caso de Léger. No entanto, essa busca pela "homogeneidade" - sobre a qual discorre o catálogo da Exposição de Paris, de que nos ocupamos anteriormente - convive, nesses artistas, com o esforço de se distender as fronteiras das artes. Daí porque um artista como Kandinsky ter atribuído aos seus quadros a nomenclatura retirada das composições musicais de Arnold Schönberg:"17 Fernand Léger roteirizar e aparecer em Ballet mécanique (1924) - filme que procura, desde o título, estabelecer uma analogia entre os campos da dança e da mecânica -; ou Alcântara Machado costurar sua obra a partir de referências de forma e fundo, não só ao cinema, mas às artes plásticas e à música.

A escritura de Alcântara Machado mostra-se sensível às questões formuladas pelas vanguardas, voltando-se, num só tempo, à materialidade dos signos linguísticos e à interpenetração das artes. A presença do cinema em sua obra, percebida de modo pioneiro por Cecília de Lara, já deu pasto para longas reflexões (SÜSSEKIND, 2006; GÁRATE, 2012, RODRIGUES, 2012). Não é nosso objetivo, aqui, repisar a questão, mas sim pensar nas limitações do projeto vanguardista no âmbito da literatura. Noutras palavras, como trabalhar a "materialidade" dos signos linguísticos, uma vez que eles não são objetos tangíveis ou homogêneos, como a tinta ou as formas geométricas, porém arbitrários e remetem a algo que se situa para além de si, a sentidos socialmente construídos?

Rodrigues (2012) tece algumas reflexões argutas que tocam a relação que "Pathé-Baby" estabelece com o cinema, tomando a obra como uma analogia literária ao gênero cinematográfico das "sinfonias metropolitanas": o olhar panorâmico às cidades, visando o âmbito documental, a linguagem que busca chamar a atenção sobre si, o recurso à música - já que essa sorte de filmes era montada respeitando-se a rítmica musical. Porém, a análise engenhosa da autora esbarra numa barreira temporal: Manhatta, de Charles Sheeler e Paul Strand, 1921, que a autora aponta como sendo a primeira sinfonia metropolitana, não é dotada de uma arquitetura sinfônica. A pioneira é Berlim: sinfonia da metrópole (de Walter Ruttmann), datada de 1927 - posterior, portanto, um ano da publicação de "Pathé-Baby".

17 Para mais informações sobre a relação de ambos, cf. nota 8. 
É certo, como aponta Rodrigues, que Alcântara Machado foi influenciado por uma atmosfera de época. Em Paris, possivelmente foi apresentado a artistas de vanguarda por meio do prefaciador de "PathéBaby" - Oswald de Andrade e a esposa Tarsila do Amaral habitavam a cidade à época e nutriam relações com, por exemplo, Fernand Léger (HEDEL-SAMSON, 2009). No entanto, há, supomos, indícios mais fortes a aproximarem "Pathé-Baby" da comunicativa e popular cena cinematográfica do princípio de 1910, do que do sofisticado cinema de vanguarda dosanos de1920. Em princípios de 1910, a sessão cinematográfica era composta grosso modo por curtas-metragens de temáticas e gêneros variados (comédias, melodramas, westerns, cine-jornais), cujas características em parte originaram-se do cinema de atrações, do início da cinematografia. ${ }^{18}$

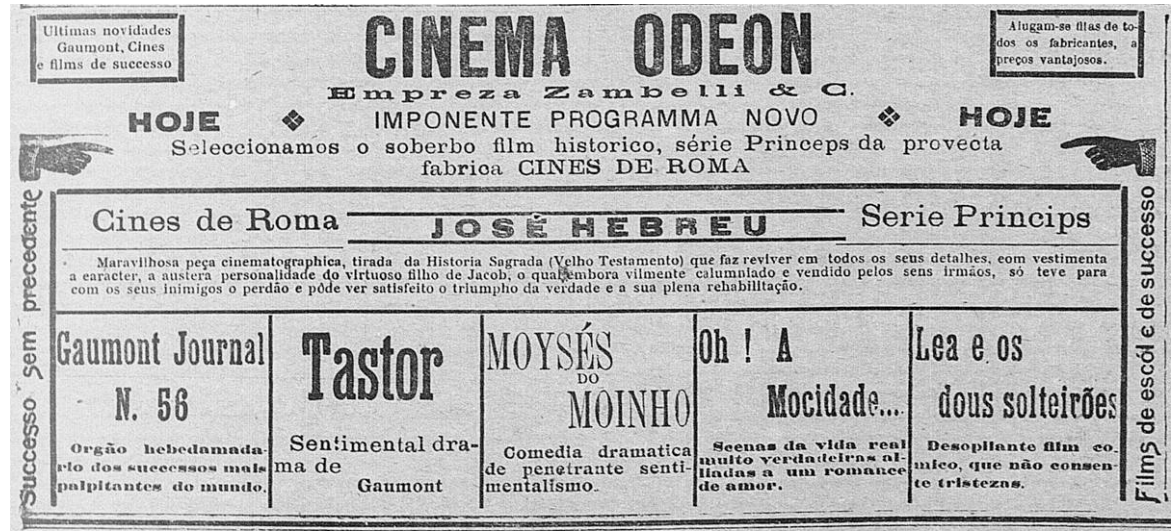

Figura 3. Anúncio do Cinema Odeon (CINEMA ODEON, 1911).

Fonte: Biblioteca Nacional Digital.

O programa cinematográfico engendrado por Alcântara Machado em seu "Pathé-Baby" comporta mais características dessa fragmentária sessão de cinema da aurora da década anterior - sessão anárquica, tributária de

18 A historiografia da área situa o "cinema de atrações" no primeiro decênio da cinematografia. Trata-se de um espetáculo composto por filmes cujo intuito era de maravilhar, chocar e/ou atrair o público, voltados mais à apresentação de múltiplas curiosidades (e, neste contexto, do próprio mecanismo reprodutor das imagens em movimento) que à representação (vertente à qual o cinema se voltaria posteriormente). Inserem-se nesse escopo as cenas de perseguição, os travelogues (cenas tomadas em grandes centros urbanos ou em localidades pitorescas), os números circenses captados pelas lentes do cinematógrafo - aos quais denominávamos "vistas", e não por acaso, já que existiam para "darem a ver" seus objetos, levando o público a conhecer o mundo (GAUDREAULT, 2008, p. 93). 
espetáculos populares historicamente estigmatizados, como a pantomima circense e o vaudeville - do que da sessão domesticada que se consolidaria na medida em que caminhavam os anos de 1910, burilada de acordo com a narrativa clássica. Miriam Hansen (1991, p. 23) debruça-se sobre essa passagem em Babel and Babylon, obra em que ela refaz o percurso de Hollywood visando ao estabelecimento da linguagem cinematográfica clássica e, por conseguinte, à construção de um espectador unívoco (daí a evolução nos enquadramentos, edição e encenação no intuito de dirigir o olhar do público para uma interpretação específica), esforço engendrado no interior de um processo complexo que relacionava produção, distribuição e exibição. ${ }^{19}$

Mesmoa estratégia anunciativa dos filmes que compõem o "Programa" de "Pathé-Baby" se assemelha àquela do cinema que o seu jovem escritor via quando menino: o uso de tipos gráficos das mais variadas formas e tamanhos, no intuito de destacar as obras que compõem o programa; a prodigalidade da adjetivação das fitas (Barcelona é descrita como "película de sensação em 2 partes” etc.). É certo que perpassa o livro uma ironia ausente naqueles objetos primeiros - ironia que lê antropofagicamente o espetáculo popular, numa apropriação que não deixa de lado o viés crítico (e exemplos são a incabível quantidade de partes do "programa" 23; ou a adjetivação das mesmas, a contrapelo do que elas objetivamente enunciam - o tônus demolidor dado ao filme-capítulo "FLORença", por exemplo, de modo algum remete ao aspecto floral alusivo à tipologia utilizada para anunciá-lo). Reportando-se a Tom Gunning, Hansen (1991, p. 24) sublinha a presença de estratégias enunciativas do cinema de atrações na cinematografia vanguardista. Voltando-nos à obra da qual nos ocupamos - uma proposta de cinema no campo da literatura -, é patente a inclinação de seu autor ao travelogue, à mostra vagabunda dos sítios inerente ao cinema de atração.

E, ao se apropriar da mise-en-scène desse cinema, Alcântara Machado apresenta uma proposta literária visando à efetivação do projeto vanguardista no que tange à literatura. Ao contrário de outras artes, como a pintura ou a escultura, as quais poderiam prescindir dos sentidos, voltando-se unicamente ao trabalho com a materialidade das formas, a literatura apenas se realiza quando forja os seus signos na direção de um sentido - mesmo fragmentário. "Pathé-Baby" constrói um entre-lugar. Ao chamar atenção à forma por meio da qual se forja o texto, põe em destaquea

19 Processo que, segundo ela, completa-se em 1917 (HANSEN, 1991, p. 23).

Remate de Males, Campinas-SP, v. 37, n. 1, pp. 385-407, jan./jun. 2017 
arbitrariedade dos signos utilizados para comporem as narrativas. Porém, não se despede da narratividade. Daí a aproximação que aventamos, no item anterior deste artigo, entre a proposta estética de Alcântara Machado e L'inhumaine, o filme vanguardista, de Marcel L'Herbier, que não esconde os seus liames com o popular gênero melodramático. O subcapítulo final de "Pathé-Baby", atinente à cidade de Florença e denominado "concerto", mostra o jogo duplo. Embora composto por elipses que todo o tempo fragmentam o texto, ele atinge, quando visto como um todo, uma costura sincopada que, ao invés de esfarelar o sentido do conjunto, dá-lhe uma calidez embalante, poética e muito pessoal - na qual se misturam em polifonia os sons ambientes:

Avança a serenata, com sons tristes.

Mia um gato e o corcunda canta. Scettico blues. A melodia italiana latiniza melancolicamente o ritmo norte-americano.

Quando il mio primo amore

mi sconvolse la vita...

A voz do corcunda lacrimeja. Grave e quente. Exala alma. Os bandolins tremem mais alto

(MACHADO, 2002, p. 114).

Os períodos acima lembram, à primeira vista, takes cinematográficos. No entanto, sobrepõem-se à objetividade técnica do olho da câmera passaremos aqui ao largo da reflexão sobre o que seja tal objetividade, também ela questionável - devido à materialidade do código linguístico. Ao contrário da objetiva ação da luz sobre a superfície, matéria de que é feito o cinema, o que temos na literatura são arranjos, sobre o papel, de signos cujos sentidos foram e continuam a ser decididos historicamente. A linguagem verbal atua de modo dessemelhante da linguagem cinematográfica, ao, por exemplo, só poder trabalhar a onipresença de modo figurado, uma vez que é obrigada a alinhar as palavras umas após as outras - tal alinhamento comportando escolhas e juízos de valor do autor. $^{20}$

Assim, no trecho que tomamos como exemplo, Alcântara Machado produz um piegas que ri de si mesmo, traço que será uma constante em sua prosa literária escrita a partir de "Pathé-Baby" - obra que, não por acaso, chistosamente se fecha com uma "moralidade" bem ao gosto do lirismo nacional: o segundo quarteto da "Canção do exílio", do romântico

20 No que diz respeito às reflexões modernistas sobre simultaneidade e polifonia, atentese para o capítulo "Modernismo e Cinema", da obra de Xavier (1978, pp. 160-163).

Remate de Males, Campinas-SP, v. 37, n. 1, pp. 385-407, jan./jun. 2017 
Gonçalves Dias. Esse fecho, é preciso que se sublinhe, coopera para a organicidade da estética do autor modernista, homem para quem os pressupostos das vanguardas europeias submetiam-se a uma sensibilidade nascida e criada em solo brasileiro. Sensibilidade miscigenada, como miscigenada era a sua cultura natal: composta de elementos europeus, africanos e, enfim, do elemento norte-americano, introduzido no contexto primevo de globalização. A ruptura que o autor propõe a "PathéBaby" e estende a Brás, Bexiga e Barra-Funda (1927) e a Laranja da China (1928) procura divorciar-se não da narratividade, mas da narrativa que estrutura sua forma e conteúdo a partir dos parâmetros clássicos nascidos na Europa e impostos unilateralmente ao longo dos séculos.

\section{REFERÊNCIAS BIBLIOGRÁFICAS}

AMARAL, Aracy A. (1998). Antônio Paim Vieira. In: Artes plásticas na Semana de 22. $5^{\text {a }}$ ed., rev. e ampl. São Paulo: Editora 34, 2005, pp. 259-26o.

ANDRADE, Mário de. Ode ao burguês. In: De Pauliceia Desvairada a Café. São Paulo: Círculo do Livro, 1983.

APOLLINAIRE, Guillaume. Calligramme: poèmes de la paix et de la guerre (1913-1916). Paris: Mercure de France, 1918.

AUERBACH, Erich. Mimesis. São Paulo: Perspectiva, 1971.

CÂNDIDO, Antonio. Dialética da malandragem: caracterização das Memórias de um sargento de milícias. Revista do Instituto de Estudos Brasileiros, São Paulo, USP, no 8, 1970, pp. 67-89.

CARVALHO, Danielle C. A poesia da cidade moderna: uma leitura de "Rien que les Heures" (1926), de Alberto Cavalcanti. Intexto, Rio Grande do Sul, UFRGS, n. 26, 2002, pp. 132-150. Disponível em: <http://seer.ufrgs.br/index.php/intexto/article/ view/26247>. Acesso em: 28 mar. 2017.

CARVALHO, Danielle C. Luz e sombra no écran: realidade, cinema e rua nas crônicas cariocas de 1894 a 1922. 2 vols. Tese de Doutorado em Teoria e História Literária - Instituto de Estudos da Linguagem (IEL). Universidade Estadual de Campinas, Unicamp, Campinas, 2014.

CAVALCANTI, Plínio. Entre samambaias, tucanos e mal-me-queres. Ilustração Brasileira, no 93,1928 , [s.p.].

CINEMA ODEON. Gazeta de Notícias, Rio de Janeiro, 1 dez. 1911, p. 10. 
"Pathé-baby": os deslizamentos da prosa turística de Alcântara Machado - 406

COELHO, João Marcos. Schönberg, Kandinsky e uma nova arte. Concerto, São Paulo, ago. 2015, p. 24.

DIMAS, Antonio. Ambiguidade da crônica: literatura ou jornalismo? Revista Littera, ㄲo 12, set.-dez. 1974, pp. 46-49.

EDISONINA (pseud. de Elvira Gama). Kinetoscópio. Jornal do Brasil, Rio de Janeiro, 23 dez. 1894, p. 1.

FOSTER, Lila \& LEÃO, Roberto Souza. A presença da "Pathé-Baby” no Rio de Janeiro e a coleção Paschoal Nardone no acervo do AGCRJ. Revista do Arquivo Geral do Rio de Janeiro, no 9, 2015, pp. 341-353. Disponível em: <http://goo.gl/aFXıuq>. Acesso em: 28 mar. 2017.

FRANCE. Ministère du Commerce, de l'Industrie, des Postes et des Télégraphes (18941929). In: Exposition Internationale des Arts Décoratifs et Industriels Modernes (1925): Volume X. Théâtre. Photographie et Cinématographie (Classes 25 et 37). Paris: Libraire Larousse, 1929.

FRANCE. Exposition Internationale des Arts Décoratifs et Industriels Modernes (1925): Volume I (Rapport Général). Paris: Libraire Larousse, 1931.

GÁRATE, Miriam V. Películas de papel/crónicas de celuloide: acerca de João do Rio, Alcântara Machado y Alberto Cavalcanti. In: Wolfgang Bongers (org.). Prismas del cine latinoamericano. Santiago de Chile: CELICH: Editorial Cuarto Propio, 2012, pp. $65-90$.

GAUDREAULT, André. Cinéma et attraction. Paris: CNRS Éditions, 2008.

HANSEN, Miriam. Babel and Babylon: Spectatorship in American Silent Film. Cambridge: Harvard University Press, 1991.

HEDEL-SAMSON, Brigitte. Fernand Léger e os amigos brasileiros. In: HEDEL-SAMSON, Brigitte (curadora); BARROS, Regina Teixeira de (curadora adjunta). Fernand Léger: relações e amizades brasileiras. São Paulo: Pinacoteca do Estado de São Paulo / Imprensa Oficial do Estado de São Paulo, 2009, pp. 13-32.

JOÃO DO RIO. João do Rio, Antologia de contos. Orna Messer Levin (org. e apresentação), Danielle Crepaldi Carvalho (estabelecimento de texto e notas). São Paulo: Lazuli Editora / Companhia Editora Nacional, 2010.

JOE (pseud. de Paulo Barreto/ João do Rio). Cinematógrafo. Gazeta de Notícias, Rio de Janeiro, 11 ago. 1907, p. 1.

KLAXON: mensário de arte moderna. № 1. São Paulo, 15 mai. 1922.

LARA, Cecília de. Considerações gerais. In: MACHADO, António de Alcântara. PathéBaby. Edição fac-similar comemorativa dos 80 anos da Semana de Arte Moderna (1922-2002). Rio de Janeiro / Belo Horizonte: Livraria Garnier, 2002. 
"Pathé-baby": os deslizamentos da prosa turística de Alcântara Machado - 407

L'INHUMAINE. Direção de Marcel l'Herbier. Produção de Marie-Laure de Noailles. França, Cinégraphic, 1924. DVD.

MACHADO, António de Alcântara. Pathé-Baby: panoramas internacionais: III-Lisboa. Jornal do Comércio, São Paulo, 12 mai. 1925, pp. 3-4.

MACHADO, António de Alcântara. Obras v. 1: Prosa preparatória \& Cavaquinho e saxofone. Direção e colaboração de Francisco de Assis Barbosa; texto e organização de Cecília de Lara. Rio de Janeiro: Editora Civilização Brasileira, 1983.

MACHADO, António de Alcântara. Pathé-Baby. Edição fac-similar comemorativa dos 80 anos da Semana de Arte Moderna (1922-2002). Rio de Janeiro / Belo Horizonte: Livraria Garnier, 2002.

MACHADO JR. Rubens L. R. São Paulo em movimento: a representação cinematográfica da metrópole nos anos 20. Tese de Mestrado em Artes. Escola de Comunicações e Artes, Universidade de São Paulo, USP, São Paulo, 1989.

MALLET-STEVENS, Rob. L’Exposition des Arts Décoratifs à Paris en 1925. Le blog des Amis de la Villa Cavrois._[S.d.]. Disponível em: <http://goo.gl/g8TI4W>. Acesso em: 28 mar. 2017.

MORETTIN, Eduardo. V. A cultura cinematográfica nas exposições universais: modernidade e tradição na Paris de 1925. Galáxia, São Paulo, no 30, dez. 2015. Disponível em: <http://dx.doi.org/10.159o/1982-25542015222289>. Acesso em: 28 mar. 2017.

MORETTIN, Eduardo. V. Dimensões históricas do documentário brasileiro no período silencioso. Revista Brasileira de História, São Paulo, v. 25, no 49, 2005. Disponível em: <http://goo.gl/PXhAPD<. Acesso em: 28 mar. 2017.

N. (pseud. de Coelho Netto). Instantâneos. Correio da Manhã, Rio de Janeiro, 1 jun. 1904, p. 1.

PINACOTECA de São Paulo. A paisagem na arte: 1690-1998. Artistas britânicos na coleção da Tate, 2015. Disponível em: <http://pinacoteca.org.br/programacao/a-paisagemna-arte-1690-1998-artistas-britanicos-na-colecao-da-tate/>. Acesso em: 28 mar. 2017 .

RODRIGUES, Ana Paula Dias. António de Alcântara Machado com a câmera: exploração geográfica e cinematografia em "Pathé-Baby". Cadernos de Semiótica Aplicada, v. 10, no 2, dez. 2012. Disponível em: <http://seer.fclar.unesp.br/casa/article/view/5580>. Acesso em: 28 mar. 2017.

SÜSSEKIND, Flora. (1987). Cinematógrafo de letras. São Paulo: Cia. das Letras, 2006.

XAVIER, Ismail. Sétima Arte: um culto moderno. São Paulo: Perspectiva / Secretaria da Cultura, Ciência e Tecnologia do Estado de São Paulo, 1978. 